\title{
microRNA-664 enhances proliferation, migration and invasion of lung cancer cells
}

\author{
XINHAI ZHU, SHENG JU, FENG YUAN, GUOPING CHEN, YUE SHU, \\ CHUANCHUAN LI, YANHUI XU, JING LUO and LILONG XIA
}

Department of Thoracic Surgery, Zhejiang Hospital, Hangzhou, Zhejiang 310000, P.R. China

Received December 27, 2015; Accepted February 3, 2017

DOI: $10.3892 /$ etm.2017.4433

\begin{abstract}
Altered microRNA (miR) expression serves an important role in the development and progression of lung cancer. In the present study, the effect of miR-664 on proliferation, migration and invasion of lung cancer cells was assessed. The proliferation of lung cancer cells with an overexpression of miR-664 was examined via MTT assay. The Caspase-Glo3/7 assay was used to examine the effect of miR-664 on cisplatin-induced apoptosis in lung cancer cells. The migration and invasion of lung cancer cells were assessed by Transwell migration and matrigel invasion assays. Western blot analysis was used to examine the protein expression levels. miR-664 improved the proliferation of lung cancer cells and inhibited cisplatin-induced apoptosis of A549 and A427 cells. Furthermore, altered expression of miR-664 affected migration and invasion of lung cancer cells. In addition, a miR-664 mimic decreased E-cadherin expression and increased vementin and Snail expression in lung cancer cells. Notably, the expression level of protein kinase B in A549 cells was changed following altered expression of miR-664. The results of the present study suggest that miR-664 serves an essential role in tumor development and progression in lung cancer.
\end{abstract}

\section{Introduction}

Lung cancer is the most common cause of cancer-related mortality worldwide (1), and is characterized by early distant metastasis, high mortality and poor prognosis. Only $18 \%$ of lung cancer patients survive 5 years $(2,3)$. Lung cancer may be subdivided into small-cell lung carcinoma and non-small-cell lung carcinoma (NSCLC). Of NSCLC, $40 \%$ of cases are lung adenocarcinoma, which begins in pre-cursor cells that would normally secrete substances such as mucus (4). This type

Correspondence to: Dr Xinhai Zhu, Department of Thoracic Surgery, Zhejiang Hospital, 12 Lingyin Road, Hangzhou, Zhejiang 310000, P.R. China

E-mail: xinhai.zhu@aol.com

Key words: protein kinase B, apoptosis, metastasis, microRNA, microRNA-664 of lung cancer occurs in smokers (54\%) and non-smokers $(8 \%)$ (5). However, it is more common in females than males to develop NSCLC than other types of lung cancer. Surgery is the major treatment for patients with stage I and II NSCLC. Cisplatin-based adjuvant chemotherapy has markedly improved progression-free survival following surgery. Cisplatin has been the most common treatment for patients with stage III and stage IV NSCLC (6). It has been reported that concurrent chemoradiotherapy may improve the median survival and long-term disease-free survival $(7,8)$. However, its overall response rate is only $30-40 \%$, median survival time is $\sim 9$ months and the 1-year overall survival rate is 30-40\% (9). Therefore, research efforts have focused on identifying molecular targets and developing molecular-targeted therapies $(4,10,11)$.

microRNAs (miRNAs or miRs) are a family of small non-coding RNAs, which are 18-22 nucleotides in length. Studies have reported that miRNAs serve important roles in tumorigenesis, progression, diagnosis and prognosis of lung cancer. Aberrant miRNA expression, such as miR-15a (12), miR-16 (12), miR-34a (13), miR-34b (14) and miR-125 (15), are important factors affecting the proliferation of lung cancer cells. Ectopic expression of miR-212 influences apoptosis in lung cancer cells (16). Previous studies have reported that miRNAs may be used as prognostic biomarkers in lung cancer: Using reverse transcription-quantitative polymerase chain reaction (RT-qPCR) assays, the dynamic change of miRNAs is determined from the serum of patients with NSCLC (17-19).

The expression of miR-664 is increased in certain types of cancer, including lung cancer. However, the mechanism of miR-664 in regulating lung tumorigenesis is unclear $(20,21)$. In the present study, the role of miR-664 in lung cancer cells was examined. Overexpression of miR-664 was demonstrated to promote proliferation, migration and invasion of lung cancer cells. Notably, miR-664 enhanced the epithelial-mesenchymal transition (EMT) of lung cancer cells by targeting protein kinase $\mathrm{B}(\mathrm{AKT})$. The results of the present study indicate that miR-664 may be a potential biomarker to predict the prognosis of lung cancer and may be a target for novel therapeutic strategies.

\section{Materials and methods}

Cell lines and cell culture. Human lung adenocarcinoma epithelial cell lines A549 and A427 obtained from American 
Type Culture Collection (Manassas, VA, USA) were grown in Dulbecco's modified Eagle's medium (DMEM; Gibco; Thermo Fisher Scientific, Inc., Waltham, MA, USA) containing 10\% fetal bovine serum (FBS; Invitrogen; Thermo Fisher Scientific, Inc.) and penicillin $(1 \mathrm{U} / \mathrm{ml})$ and streptomycin $(1 \mathrm{mg} / \mathrm{ml})$ at $37^{\circ} \mathrm{C}$ and $5 \% \mathrm{CO}_{2}$ in a $95 \%$ humidity incubator. All cells were passaged when they reached $\sim 80 \%$ confluence.

Transfection. miR-664 mimics (catalogue no. B01001-132) and anti-miR-664 inhibitor (catalogue no. B03001-155) were purchased from Shanghai GenePharma Co., Ltd. (Shanghai, China). The miR-664 mimic (30 pM) or anti-miR-664 inhibitor $(20 \mathrm{pM})$ was transfected to lung cancer cells using Lipofectamine 2000 (Invitrogen, USA) according to the manufacturer's protocol, when the A549 and A427 cells reached $70-80 \%$ confluence. The scrambled oligonucleotide (B04001-12; Shanghai GenePharma Co., Ltd.) was used as negative control.

$R T$-qPCR of $m i R-664$. Total RNA was prepared using the RNeasy Mini kit (Qiagen GmbH, Hilden, Germany) according to the manufacturer's protocol. Taqman MicroRNA Reverse Transcription kit (Thermo Fisher Scientific, Inc., Waltham, MA, USA) was used to make cDNA from the total RNA (200 ng). The PCR conditions were as follows: $95^{\circ} \mathrm{C}$ for $5 \mathrm{~min}$, followed by 30 cycles of $95^{\circ} \mathrm{C}$ for $30 \mathrm{sec}$ and $60^{\circ} \mathrm{C}$ for $30 \mathrm{sec}$ and a dissociation stage. PCR was performed using TaqMan Universal PCR master Mix according to the manufacture's protocol (Thermo Fisher Scientific, Inc.) with a Bio-Rad CFX96 Real-Time PCR machine (Bio-Rad Laboratories, Inc., Hercules, CA, USA). GAPDH was used for RNA quantification, using the $2^{-\Delta \Delta \mathrm{Cq}}$ method as descripted previously (22). The sequences of PCR primers used were as follows: 5'-TAC AACACCGGTCACTAACGCATTG-3' and 5'GTATCACCT CCTCCAGCAACTAACA-3' (miR-664 mimic), 5'-CAGTAT CATTCTGTCGCGCTTGTTTA-3' and 5'-TCGGGCGCA ATAATGTAGCGA-3' (miR-664 inhibitor) and 5'-GTCTCC TCTGACTTCAACAGCG-3' and 5'-ACCACCCTGTTGCTG TAGCCAA-3' (GAPDH). All miRNA TaqMan primers were purchased from Ambion; Thermo Fisher Scientific, Inc.

The effect of miR-664 on cell proliferation. An MTT assay (23) was performed to evaluate the effect of miR-664 on the proliferation of lung cancer cells. Either scrambled oligonucleotide or miR-664 mimic was transfected to the two lung cancer cell lines and the cells were grown in 96-well culture plates at a density of $2 \times 10^{4}$ cells/well. Growth medium (DMEM) containing MTT $(20 \mu \mathrm{l}, 5 \mathrm{mg} / \mathrm{ml})$ was added to each well and cultured for $4 \mathrm{~h}$ at $37^{\circ} \mathrm{C}$, the medium was changed every other day. Subsequently, $100 \mu 1$ dimethyl sulfoxide was added to each well and cultured for a further 10 min with gentle agitation at room temperature. The absorbance was measured at $490 \mathrm{~nm}$ at room temperature using ELx800 Absorbance Reader (BioTek Instruments, Inc., Winooski, VT, USA). All experiments were performed in triplicate.

The effect of miR-664 on apoptosis. A549 cells overexpressed with either scrambled oligonucleotide or miR-664 mimic were seeded in 24-well culture plates at a density of $2 \times 10^{5}$ cell/well. Following $12 \mathrm{~h}$ of culture, DMEM medium containing 2,5 and
$10 \mu \mathrm{mol} / 1$ cisplatin (Sigma-Aldrich; Merck KGaG, Darmstadt, Germany) was added to each well (according to the concentrations in previous killing curve experiments; data not shown) and culturing continued for a further $72 \mathrm{~h}$ at $37^{\circ} \mathrm{C}$ and $5 \% \mathrm{CO}_{2}$ in a $95 \%$ humidity incubator. The caspase $3 / 7$ activity was examined according to the following protocol: Caspase-Glo reagent (Promega Corporation, Madison, WI, USA) was directly added to each well and incubated for $8 \mathrm{~h}$ with gentle agitation at room temperature. The Multiskan ${ }^{\mathrm{TM}}$ FC Microplate Photometer (Thermo Fisher Scientific, Inc.) was used to examine the caspase $3 / 7$ activity using $1 \mathrm{~min}$ lag time and $0.5 \mathrm{sec} /$ well reads. The experiments were performed in triplicate.

Matrigel invasion assays. To evaluate the effect of miR-664 on migration and invasion of lung cancer cells, a matrigel invasion assay, using invasion and migration chambers purchased from BD Biosciences (Franklin Lakes, NJ, USA) was performed according to the manufacturer's protocol. To evaluate migration, the Transwell insert without matrigel was used. Briefly, either miR-664 mimic or anti-miR-664 inhibitor was transfected to the two lung cancer cell lines and $1 \times 10^{4}$ cells were seeded to the upper chambers in $0.5 \mathrm{ml}$ DMEM with $0.1 \%$ bovine serum albumin. DMEM medium $(700 \mu \mathrm{l})$ containing 5\% FBS was added to the lower chamber. A cotton swab was used to remove the non-invaded cells $12 \mathrm{~h}$ later. The invaded cells were stained using Diff Quik solution (Thermo Fisher Scientific, Inc.). Data is expressed as the percent of invasion through the Matrigel Matrix and membrane relative to the migration of cells through the uncoated membrane.

Western blot analysis. The transfected A549 cells were lysed with cold radioimmunoprecipitation assay buffer (Beyotime Institute of Biotechnology, Haimen, China). Then the lysis buffer was mixed with the loading buffer (Beyotime Institute of Biotechnology, Haimen, China) and boiled at $100^{\circ} \mathrm{C}$ for $5 \mathrm{~min}$. The protein concentration was assessed using a BCA protein assay kit (Thermo Fisher Scientific, Inc.) according to the manufacturer's protocol. SDS-PAGE (10\%) was used to separate the proteins $(30 \mu \mathrm{g})$, prior to being transferred to polyvinylidene fluoride membranes (Sigma-Aldrich; Merck KGaA, Darmstadt, Germany). Following blocking for $1 \mathrm{~h}$ at room temperature in 5\% non-fat dry milk in Tris-buffered saline Tween-20 (TBST) buffer, the membranes were washed with TBST buffer and incubated overnight at $4^{\circ} \mathrm{C}$ with primary antibodies against the following: B-cell lymphoma-2 (Bcl-2, 1:1,000; sc-7382), Bcl-2 associated X protein (Bax; 1:1,000) (both from Santa Cruz Biotechnology, Inc., Dallas, TX, USA), and E-cadherin (3195; 1:1,000), N-cadherin (13116; 1:3,000), vimentin $(5741 ; 1: 3,000)$, Snail (3897; 1:2,000), AKT (9272; 1:1,000), phosphorylated-AKT (p-AKT; 9271; 1:1,000) and phosphatase and tensin homolog (PTEN; 9559; 1:1,000) (all from Cell Signaling Technology, Inc., Danvers, MA, USA) in TBST with gentle agitation. Following washing with TBST at room temperature three times, the membranes were incubated with anti-rabbit secondary antibody (catalogue no. 7074; 1:3,000) or anti-mouse secondary antibody (catalogue no. 7076; 1:3,000; Cell Signaling Technology, Inc.) at room temperature for $\geq 60$ min with gentle agitation. The Pierce Western Blot Signal Enhancer (Thermo Fisher Scientific, USA) was used 

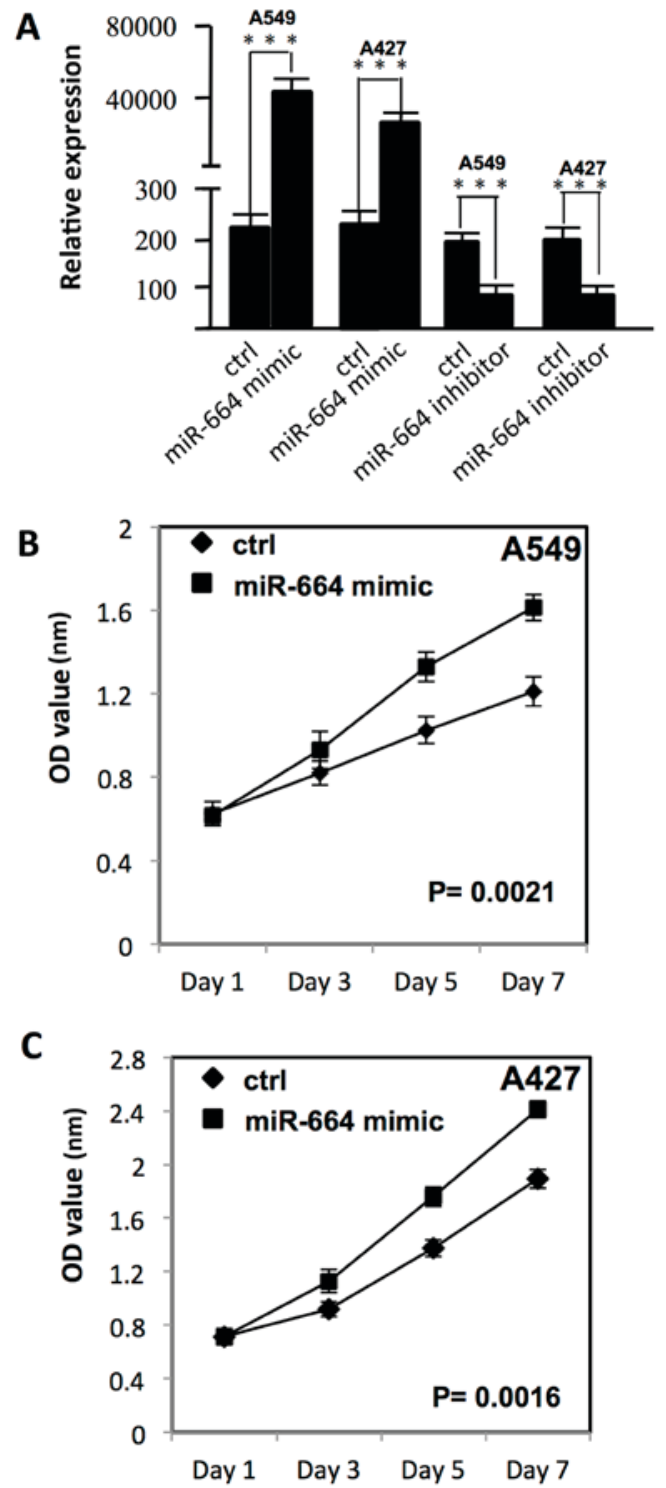

Figure 1. miR-664 decreases the chemo-sensitivity of lung cancer cells. (A) miR-664 expression level was examined using reverse transcription-quantitative polymerase chain reaction on lung cancer cells transfected with either miR-664 mimic or miR-664 inhibitor. ${ }^{* * * *} \mathrm{P}<0.05$ vs. control. (B) Proliferation of A549 cells following transfection with a miR-664 mimic. (C) Proliferation of A427 cells following transfection with miR-664 mimic. miR, micro RNA; ctrl, control; OD, optical density.

to develop the immune blot signals. To analyze the relative expression level of each protein, densitometric analysis was performed using ImageLab software version 4.1 (Bio-Rad Laboratories, Inc.). According to the manufacturer's protocol.

Statistical analysis. SPSS version 12.0 (SPSS, Inc., Chicago, IL, USA) was used for statistical analysis by Student's t-test. $\mathrm{P}<0.05$ was considered to indicate a statistically significant difference.

\section{Results}

miR-664 promotes the proliferation of lung cancer cells. To examine the effect of miR-664 on the proliferation of A549 and A427 cells, miR-664 was transfected into A549 and A427 cells with Lipofectamine 2000. MTT assay was used to measure the
A

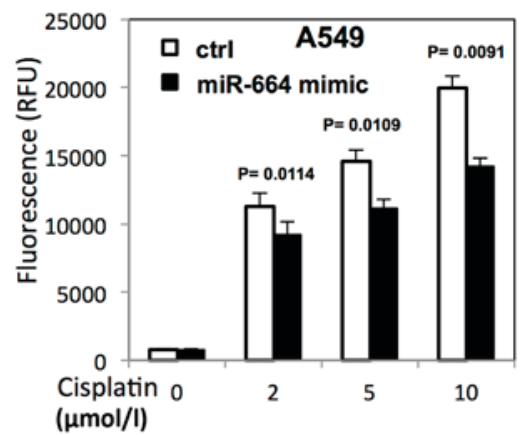

B

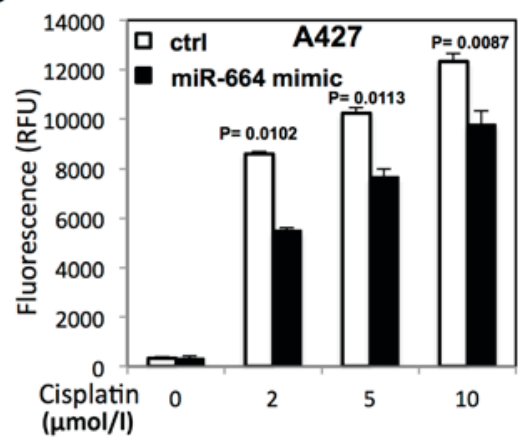

C
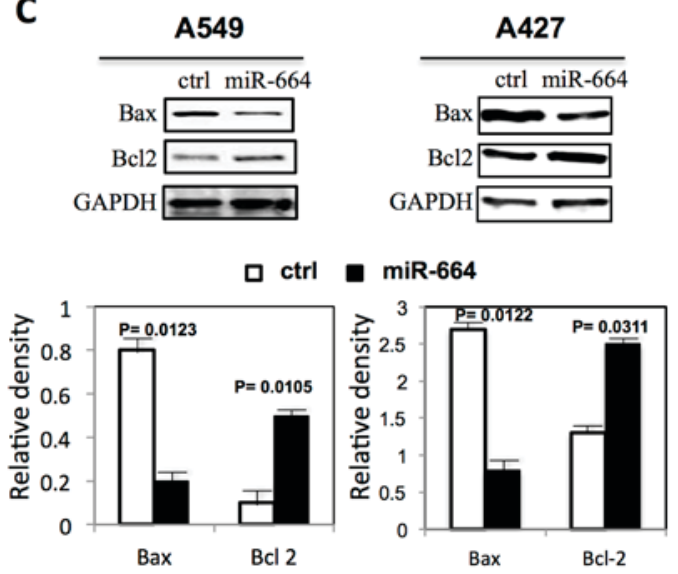

Figure 2. miR-664 decreases apoptosis in lung cancer cells. (A) Caspase 3/7 activity in A549 cells transfected with miR-664 following cisplatin treatment. (B) Caspase 3/7 activity in A427 cells transfected with miR-664 following cisplatin treatment. (C) The level of apoptotic proteins in A549 and A427 cells following cisplatin treatment. Bar graph indicates the relative quantity of proteins on A549 and A427 cells following transfection with miR-664 mimic by densitometric analysis. $\mathrm{P}<0.05$ represents a statistically significant difference vs. control. miR, microRNA; ctrl, control; OD, optical density; RFU, relative fluorescence units; Bcl-2, B-cell lymphoma-2; Bax, $\mathrm{Bcl}-2$ associated $\mathrm{X}$ protein.

growth curve. As presented in Fig. 1A, following transfection, the miR-664 expression level was significantly increased in A549 and A427 cells $(\mathrm{P}<0.05)$. The proliferation of A549 and A427 cells was significantly increased, as compared with the negative control group $(\mathrm{P}<0.01$; Fig. $1 \mathrm{~B}$ and $\mathrm{C})$.

miR-664 inhibits the apoptosis of lung cancer cells. The function of miR-664 on the apoptosis of A549 cells treated with cisplatin by Caspase-Glo3/7 assay was also evaluated. miR-664 significantly decreased the sensitivity of A549 and A427 cells to cisplatin by inhibiting the caspase 3/7 activities $(\mathrm{P}<0.05$; Fig. 2A and B). The expression of apoptosis-related 
A

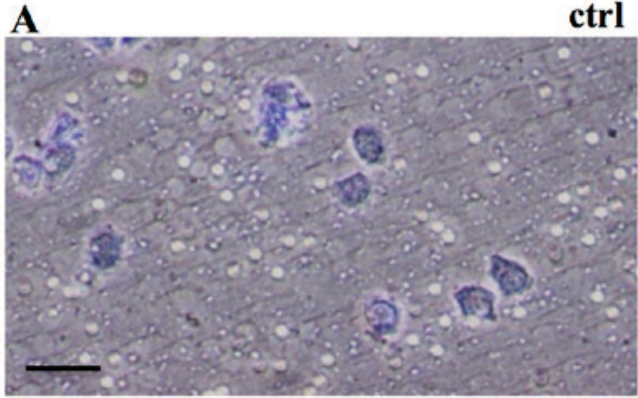

C

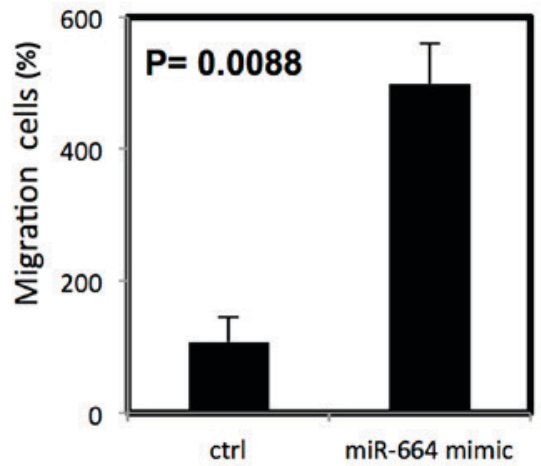

E

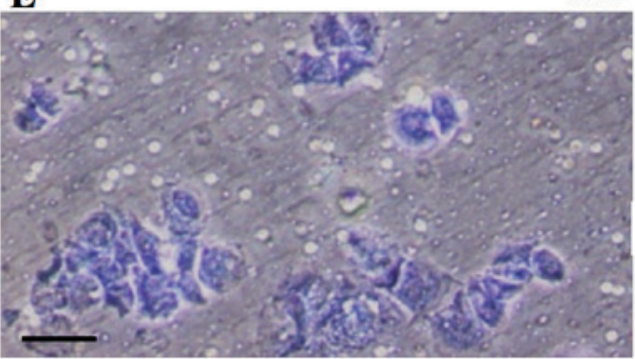

G

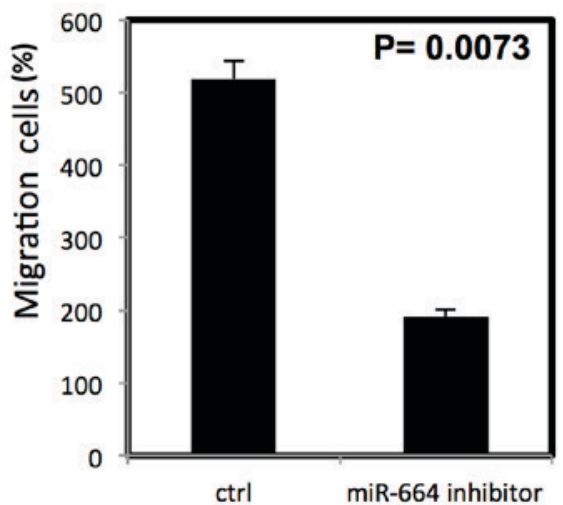

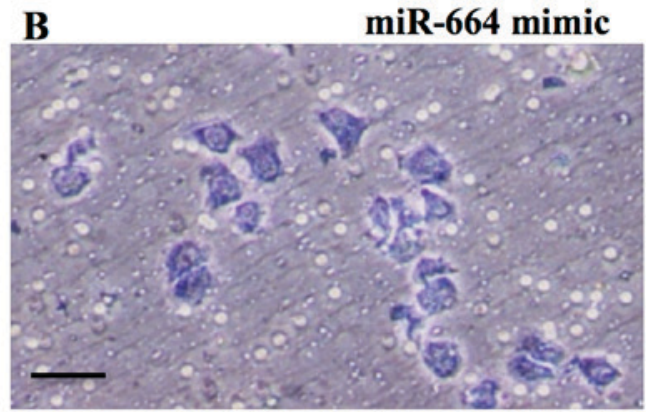

D
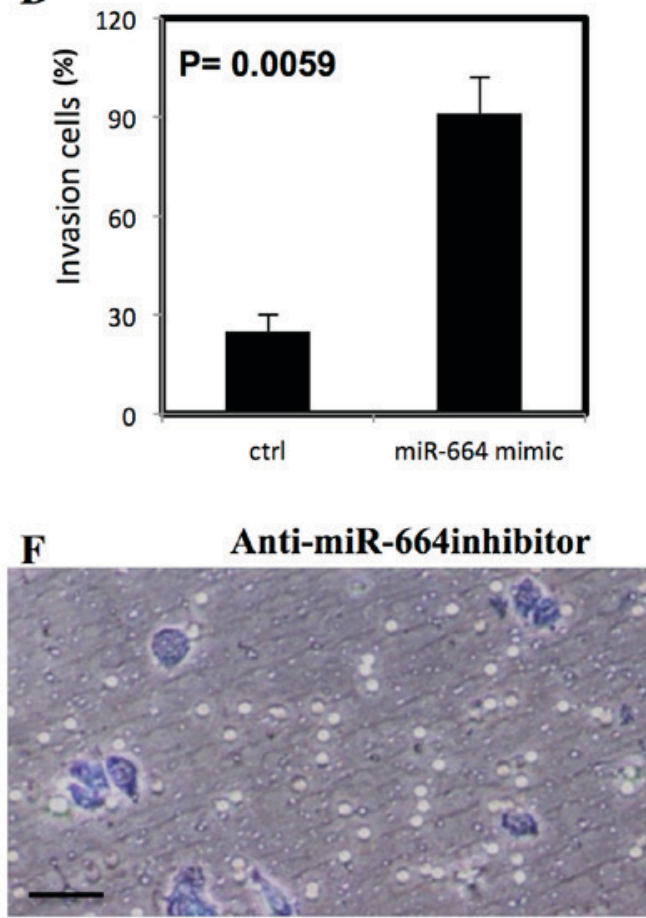

H

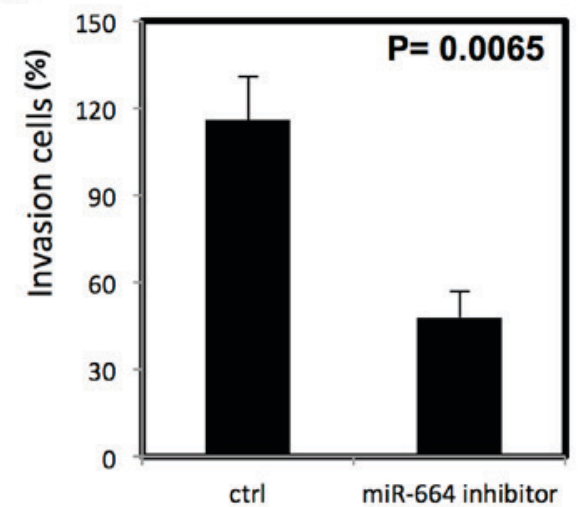

Figure 3. miR-664 increases migration and invasion of A549 cells, stained with Diff Quik stain. (A-D) miR-664 significantly increases migration and invasion of A549 cells. (E-H) Inhibitor of miR-664 significantly decreases the migration and invasion of A549 cells. All experiments were performed in triplicate, $\mathrm{P}<0.05$ represents a statistically significant difference. $\mathrm{miR}$, microRNA. Scale bar $=100 \mu \mathrm{m}$.

proteins was further analyzed by western blot analysis with or without cisplatin treatment. As presented in Fig. 2C, miR-664 significantly decreased Bax expression $(\mathrm{P}<0.05)$ and significantly increased Bcl-2 expression $(\mathrm{P}<0.05)$ in A549 and A427 cells.

miR-664 enhances the migration and invasion of lung cancer cells. To examine the effect of miR-664 on migration and invasion of lung cancer cells, Transwell migration and matrigel invasion assays were performed. The miR-664 mimic significantly increased the migration and invasion in A549 cells ( $\mathrm{P}<0.01$; Fig. 3A-D) however, the anti-miR-664 inhibitor significantly reduced the migration and invasion of A549 cells $(\mathrm{P}<0.01$; Fig. 3E-H). The significantly increased migration and invasion following treatment with miR-664 mimic was also demonstrated in A427 cells $(\mathrm{P}<0.01$; Fig. 4A-D) and a 
A

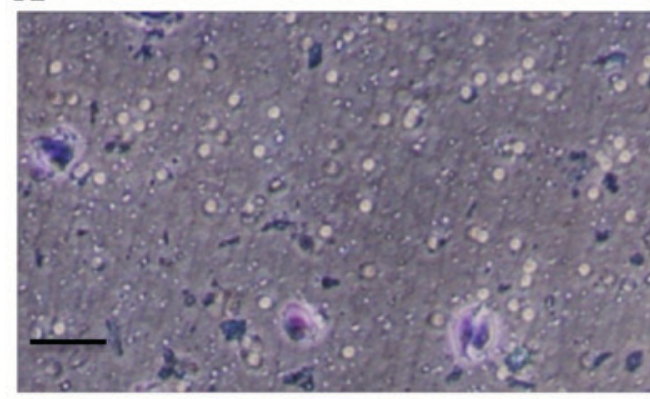

C

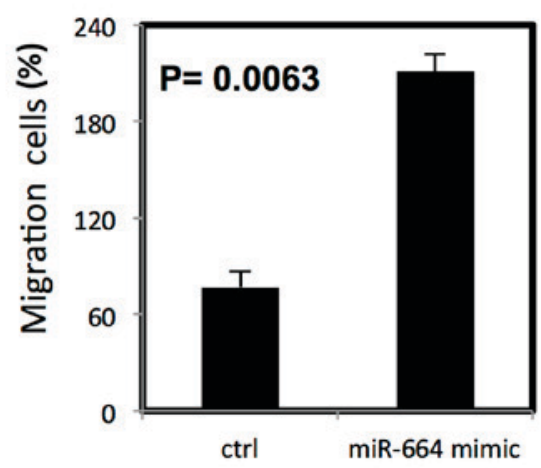

E

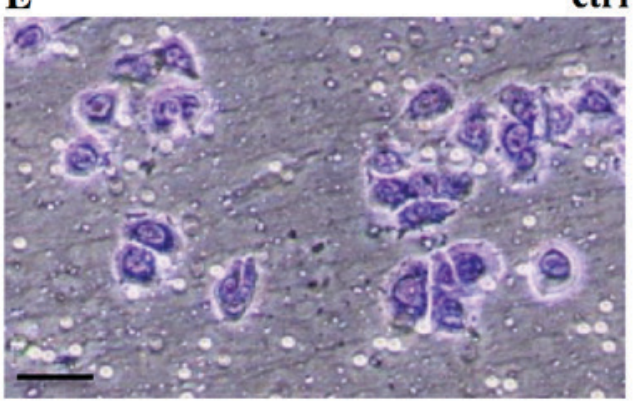

G

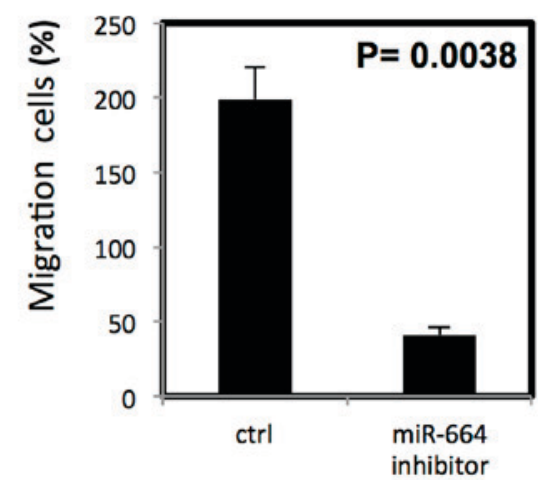

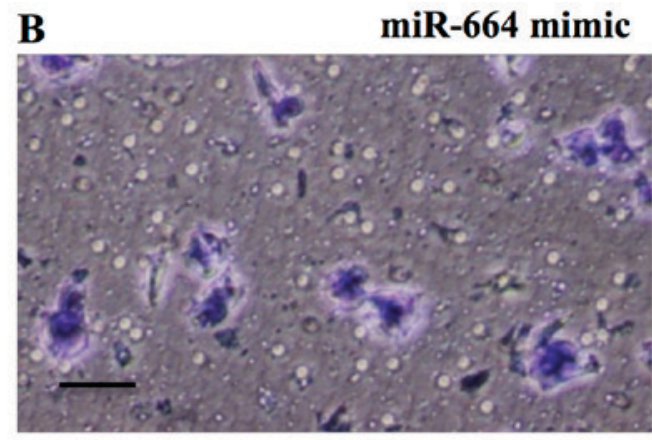

D
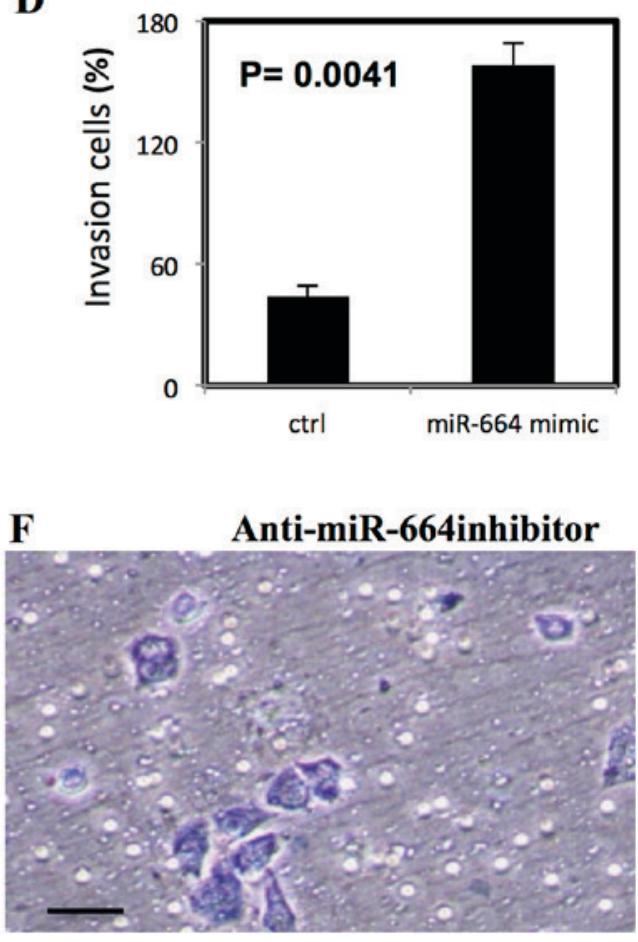

H

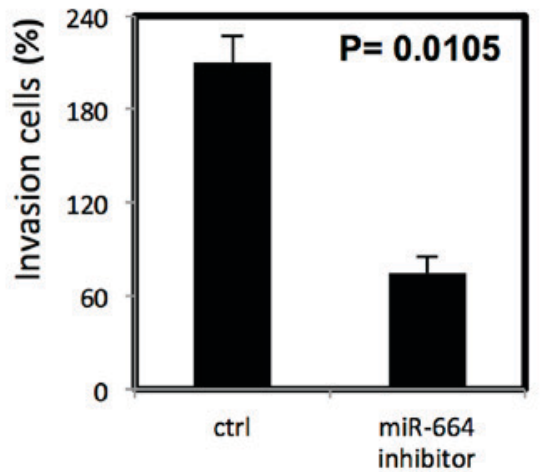

Figure 4. miR-664 increases migration and invasion of A427 cells, stained with Diff Quik stain. (A-D) Significantly increased migration and invasion of A427 cells with miR-664 treatment and (E-H) significantly decreased migration and invasion of A427 cells following treatment with miR-664 inhibitor. All experiments were performed in triplicate, $\mathrm{P}<0.05$ represents a statistically significant difference. miR, microRNA. Scale bar $=100 \mu \mathrm{m}$.

significant decrease in migration and invasion of A427 cells was observed following treatment with anti-miR-644 inhibitor $(\mathrm{P}<0.05$; Fig. 4E-H).

miR-664 affects EMT-relative proteins expression and activates AKT in A549 cells. The EMT-relative protein expression following transfection of A549 cells with either miR-664 mimic or anti-miR-664 inhibitor was subsequently examined.
The E-cadherin expression level was significantly decreased and miR-664 significantly increased the expression of $\mathrm{N}$-cadherin, Snail and vimentin in A549 cells compared with controls ( $\mathrm{P}<0.05$; Fig. 5A and $\mathrm{B})$. By contrast, following transfection of A549 cells with anti-miR-664 inhibitor, E-cadherin expression level was significantly increased $(\mathrm{P}<0.05)$, and the expression of $\mathrm{N}$-cadherin, snail and Vimentin was significantly decreased $(\mathrm{P}<0.05$; Fig. $5 \mathrm{~A}$ and $\mathrm{B})$. Notably, the 
A

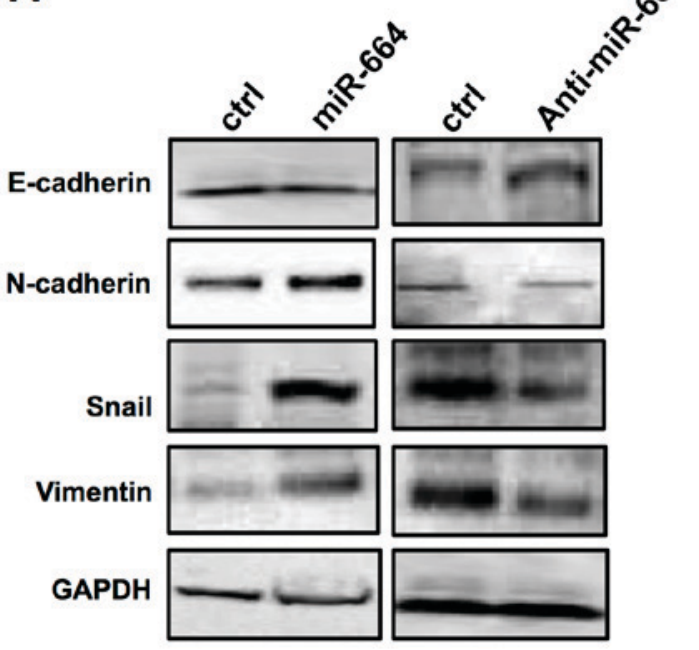

B

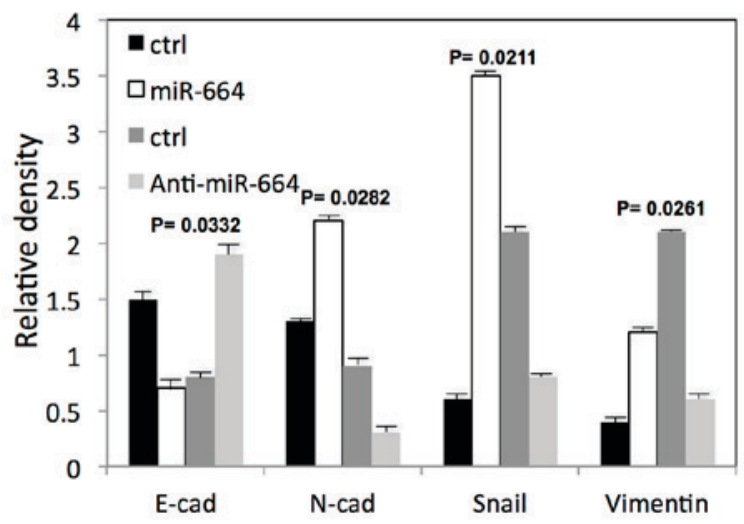

C

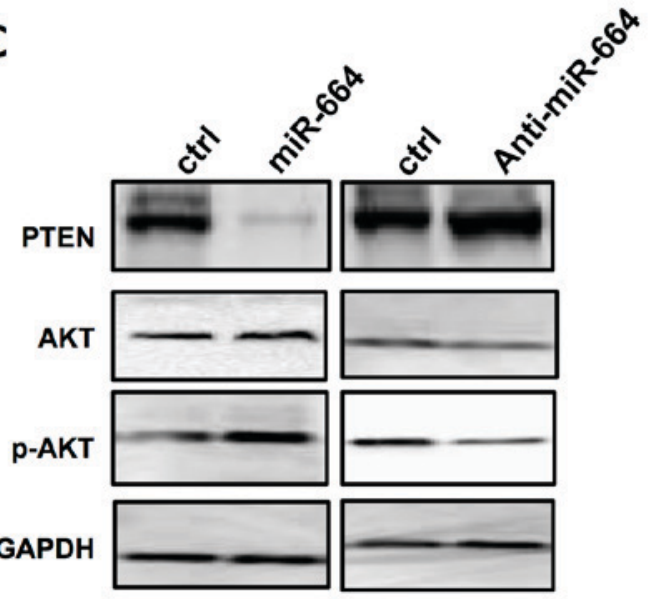

D

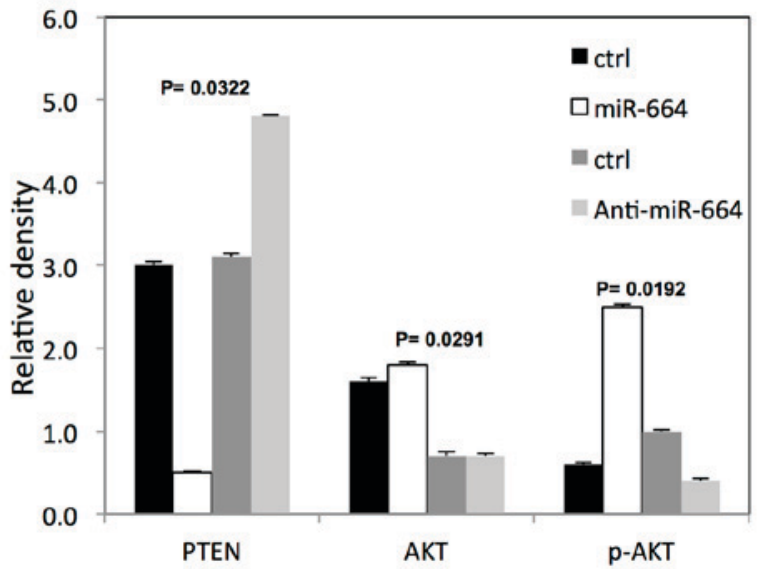

Figure 5. miR-664 regulates expression of EMT markers by activating AKT in lung cancer cells. (A) The level of EMT markers in A549 cells following transfection with either miR-664 mimic or anti-miR-664 inhibitor. (B) Bar graph indicates the relative quantity of proteins in A549 cells following transfection with miR-664 mimic by densitometric analysis. (C) Expression of AKT and PTEN in A549 cells following transfection with either miR-664 mimic or anti-miR-664 inhibitor. (D) Bar graph indicates the relative quantity of proteins in A549 cells following transfection with miR-664 mimic by densitometric analysis. P<0.05 represents a statistically significant difference. miR, microRNA; EMT, epithelial-mesenchymal transition; AKT, protein kinase B; PTEN, phosphatase and tensin homolog; Ctrl, control; E-cad, E-cadherin; N-cad, N-cadherin; p-AKT, phosphorylated-AKT.

miR-664 mimic increased $(\mathrm{P}<0.05)$ the expression of $\mathrm{p}-\mathrm{AKT}$ significantly and decreased $(\mathrm{P}<0.05)$ the PTEN expression level in A549 cells significantly $(\mathrm{P}<0.05$; Fig. $5 \mathrm{C}$ and $\mathrm{D})$. The downregulation of miR-664 significantly decreased $(\mathrm{P}<0.05)$ p-AKT protein expression and increased PTEN expression in A549 cells significantly ( $\mathrm{P}<0.05$; Fig. $5 \mathrm{C}$ and D).

\section{Discussion}

The deregulation of miRNAs has been well studied in numerous diseases, including cancer (24-26). Calin et al (27) demonstrated that the expression of miR-15 and miR-16 are decreased in patients with leukemia and may be causally associated with the pathogenesis of chronic lymphocytic leukemia. Another previous study indicated that miR-664 serves an important role in the proliferation and invasion in T-cell acute lymphoblastic leukemia by negatively regulating proteolipid protein 2 (28). Additionally, the expression level of miR-664 is increased in patients with lung cancer (21). In the present study, miR-664 promoted the proliferation of lung cancer cells and miR-664 was demonstrated to decrease cisplatin-induced apoptosis of lung cancer cells. The inhibitory effect on apoptosis was further proved by the increased $\mathrm{Bcl}-2$ expression and decreased Bax expression. These results demonstrate that miR-664 may serve an important role in lung cancer.

The risk of distant metastasis of lung cancer is high and once metastasis occurs, it may become an incurable disease with limited survival time (29). The EMT serves an important role in metastasis and allows epithelial cells to lose their epithelial characteristics and acquire a mesenchymal phenotype (30). It has been demonstrated that miRs regulate EMT in cancer (31). Pacurari et al (32) reported that the miR-200 family serves an important role in EMT of lung cancer. The present study demonstrated that miR-664 increased the migration and invasion in A549 cells. By contrast, the 
migration and invasion of A549 cells was decreased with the downregulation of miR-664. Furthermore, the present study revealed that miR-664 affected the expression of EMT-relative proteins. Therefore, the present results suggest that miR-664 serves an important role in lung cancer progression.

It has been demonstrated that AKT acts as a survival kinase, and its expression increases in numerous types of cancer, including lung cancer (33). AKT may be activated by a loss of PTEN, which is a well-known tumor suppressor gene in various types of human cancer (34-36). It has been demonstrated that miRNAs contribute to cancer cell growth by regulating PTEN (37). In the present study, miR-664 decreased the expression of PTEN and increased the expression of p-AKT in A549 cells. The results of the present study indicate that miR-664 may regulate proliferation, migration and invasion by regulating the PTEN/AKT signaling pathway.

The present study indicates that miR-664 serves an important role in the regulation of tumorigenesis and malignant progression in lung cancer cell lines. Therefore, miR-664 may be a potential molecular target in lung cancer treatment in the future. Further study it required to examine the expression level of miR-664 in patients with lung cancer.

\section{Acknowledgements}

The present study was supported by Young Scientist Award in Hangzhou City, Zhejiang province (grant no. 2011022101).

\section{References}

1. Devesa SS, Bray F, Vizcaino AP and Parkin DM: International lung cancer trends by histologic type: Male: Female differences diminishing and adenocarcinoma rates rising. Int J Cancer 117: 294-299, 2005.

2. Greenlee RT, Hill-Harmon MB, Murray T and Thun M: Cancer statistics, 2001. CA Cancer J Clin 51: 15-36, 2001.

3. Schiller JH, Harrington D, Belani CP, Langer C, Sandler A, Krook J, Zhu J and Johnson DH; Eastern Cooperative Oncology Group: Comparison of four chemotherapy regimens for advanced non-small-cell lung cancer. N Engl J Med 346: 92-98, 2002.

4. Giaccone G, Herbst RS, Manegold C, Scagliotti G, Rosell R, Miller V, Natale RB, Schiller JH, Von Pawel J, Pluzanska A, et al: Gefitinib in combination with gemcitabine and cisplatin in advanced non-small-cell lung cancer: A phase III trial-INTACT 1. J Clin Oncol 22: 777-784, 2004.

5. Sardari Nia P, Weyler J, Colpaert C, Vermeulen P, Van Marck E and Van Schil P: Prognostic value of smoking status in operated non-small cell lung cancer. Lung Cancer 47: 351-359, 2005.

6. Zarogoulidis K, Zarogoulidis P, Darwiche K, Boutsikou E, Machairiotis N, Tsakiridis,K, Katsikogiannis N, Kougioumtzi L, Karapantzos L, Huang H and Spyratos D: Treatment of non-small cell lung cancer (NSCLC). J Thorac Dis 5 (Suppl 4): S389-S396, 2013.

7. Kim DW, Shyr Y, Shaktour B, Akerley W, Johnson DH and Choy H: Long term follow up and analysis of long term survivors in patients treated with paclitaxel-based concurrent chemo/radiation therapy for locally advanced non-small cel lung cancer. Lung Cancer 50: 235-245, 2005.

8. Naito Y, Kubota K, Nihei K, Fujii T, Yoh K, Niho S, Goto K, Ohmatsu H, Saijo N and Nishiwaki Y: Concurrent chemoradiotherapy with cisplatin and vinorelbine for stage III non-small cell lung cancer. J Thorac Oncol 3: 617-622, 2008.

9. Chen LK, Liang Y, Yang QY, Xu F, Zhou NN, Xu GC, Liu GZ and Wei WD: Triplet platinum-based combination sequential chemotherapy improves survival outcome and quality of life of advanced non-small cell lung cancer patients. Asian Pac J Cancer Prev 13: 1863-1867, 2012.
10. Ciardiello F, Caputo R, Bianco R, Damiano V, Pomatico G, De Placido S, Bianco AR and Tortora G: Antitumor effect and potentiation of cytotoxic drugs activity in human cancer cells by ZD-1839 (Iressa), an epidermal growth factor receptor-selective tyrosine kinase inhibitor. Clin Cancer Res 6: 2053-2063, 2000.

11. Crombet T, Torres L, Neninger E, Catalá M, Solano ME, Perera A, Torres O, Iznaga N, Torres F, Pérez R and Lage A: Pharmacological evaluation of humanized anti-epidermal growth factor receptor, monoclonal antibody h-R3, in patients with advanced epithelial-derived cancer. J Immunother 26: 139-148, 2003.

12. Lan F, Yue X, Ren G, Li H, Ping L, Wang Y and Xia T: miR-15a/16 enhances radiation sensitivity of non-small cell lung cancer cells by targeting the TLR1/NF- $\mathrm{KB}$ signaling pathway. Int J Radiat Oncol Biol Phys 91: 73-81, 2015.

13. Shi Y, Liu C, Liu X, Tang DG and Wang J: The microRNA miR-34a inhibits non-small cell lung cancer (NSCLC) growth and the CD44hi stem-like NSCLC cells. PLoS One 9: e90022, 2014.

14. Balca-Silva J, Sousa Neves S, Goncalves AC, Abrantes AM, Casalta-Lopes J, Botelho MF, Sarmento-Ribeiro AB and Silva HC: Effect of miR-34b overexpression on the radiosensitivity of non-small cell lung cancer cell lines. Anticancer Res 32: 1603-1609, 2012

15. Li Y, Chao Y, Fang Y, Wang J, Wang M, Zhang H, Ying M, Zhu X and Wang H: MTA1 promotes the invasion and migration of non-small cell lung cancer cells by downregulating miR-125b. J Exp Clin Cancer Res 32: 33, 2013.

16. Incoronato M, Garofalo M, Urso L, Romano G, Quintavalle C, Zanca C, Iaboni M, Nuovo G, Croce CM and Condorelli G: miR-212 increases tumor necrosis factor-related apoptosis-inducing ligand sensitivity in non-small cell lung cancer by targeting the antiapoptotic protein PED. Cancer Res 70: 3638-3646, 2010.

17. Le HB, Zhu WY, Chen DD, He JY, Huang YY, Liu XG and Zhang YK: Evaluation of dynamic change of serum miR-21 and miR-24 in pre- and post-operative lung carcinoma patients. Med Oncol 29: 3190-3197, 2012.

18. Jiang M, Zhang P, Hu G, Xiao Z, Xu F, Zhong T, Huang F, Kuang $\mathrm{H}$ and Zhang W: Relative expressions of miR-205-5p, miR-205-3p, and miR-21 in tissues and serum of non-small cell lung cancer patients. Mol Cell Biochem 383: 67-75, 2013.

19. Foss KM, Sima C, Ugolini D, Neri M, Allen KE and Weiss GJ: miR-1254 and miR-574-5p: Serum-based microRNA biomarkers for early-stage non-small cell lung cancer. J Thorac Oncol 6: 482-488, 2011.

20. Yang H, Cho ME, Li TW, Peng H, Ko KS, Mato JM and Lu SC: MicroRNAs regulate methionine adenosyltransferase 1A expression in hepatocellular carcinoma. J Clin Invest 123: 285-298, 2013.

21. Lu Y, Govindan R, Wang L, Liu PY, Goodgame B, Wen W, Sezhiyan A, Pfeifer J, Li YF, Hua X, et al: MicroRNA profiling and prediction of recurrence/relapse-free survival in stage I lung cancer. Carcinogenesis 33: 1046-1054, 2012.

22. Livak KJ and Schmittgen TD: Analysis of relative gene expression data using real-time quantitative PCR and the 2(-Delta Delta C(T)) Method. Methods 25: 402-408, 2001.

23. Maioli E, Torricelli C, Fortino V, Carlucci F, Tommassini V and Pacini A: Critical appraisal of the MTT assay in the presence of rottlerin and uncouplers. Biol Proced Online 11: 227-240, 2009.

24. Gallagher MF, Heffron CC, Laios A, O'Toole SA, Ffrench B, Smyth PC, Flavin RJ, Elbaruni SA, Spillane CD, Martin CM, et al: Suppression of cancer stemness p21-regulating mRNA and microRNA signatures in recurrent ovarian cancer patient samples. J Ovarian Res 5: 2, 2012.

25. Lee YS and Dutta A: MicroRNAs in cancer. Annu Rev Pathol 4: 199-227, 2009

26. Hayes J, Peruzzi PP and Lawler S: MicroRNAs in cancer: Biomarkers, functions and therapy. Trends Mol Med 20: 460-469, 2014.

27. Calin GA, Dumitru CD, Shimizu M, Bichi R, Zupo S, Noch E, Aldler H, Rattan S, Keating M, Rai K, et al: Frequent deletions and down-regulation of micro-RNA genes miR15 and miR16 at 13 q14 in chronic lymphocytic leukemia. Proc Natl Acad Sci USA 99: 15524-15529, 2002.

28. Zhu H, Miao MH, Ji XQ, Xue J and Shao XJ: miR-664 negatively regulates PLP2 and promotes cell proliferation and invasion in T-cell acute lymphoblastic leukaemia. Biochem Biophys Res Commun 459: 340-345, 2015. 
29. Ling DJ, Chen ZS, Zhang YD, Liao QD, Feng JX, Zhang XY and Shi TS: MicroRNA-145 inhibits lung cancer cell metastasis. Mol Med Rep 11: 3108-3114, 2015.

30. Kalluri R and Weinberg RA: The basics of epithelial-mesenchymal transition. J Clin Invest 119: 1420-1428, 2009.

31. Zaravinos A: The regulatory role of MicroRNAs in EMT and cancer. J Oncol 2015: 865816, 2015.

32. Pacurari M, Addison JB, Bondalapati N, Wan YW, Luo D, Qian Y, Castranova V, Ivanov AV and Guo NL: The microRNA-200 family targets multiple non-small cell lung cancer prognostic markers in H1299 cells and BEAS-2B cells. Int J Oncol 43: 548-560, 2013.

33. Fumarola C, Bonelli MA, Petronini PG and Alfieri RR: Targeting PI3K/AKT/mTOR pathway in non small cell lung cancer. Biochem Pharmacol 90: 197-207, 2014.

34. Andjelkovic T, Bankovic J, Milosevic Z, Stojsic J, Milinkovic V, Pesic M, Ruzdijic S and Tanic N: Concurrent alteration of p16 and PTEN tumor suppressor genes could be considered as potential molecular marker for specific subgroups of NSCLC patients. Cancer Biomark 10: 277-286, 2011.
35. Stewart DJ, Nunez MI, Jelinek J, Hong D, Gupta S, Aldaz M, Issa JP, Kurzrock R and Wistuba II: Impact of decitabine on immunohistochemistry expression of the putative tumor suppressor genes FHIT, WWOX, FUS1 and PTEN in clinical tumor samples. Clin Epigenetics 6: 13, 2014.

36. Tang YA, Chen CH, Sun HS, Cheng CP, Tseng VS, Hsu HS, Su WC, Lai WW and Wang YC: Global Oct4 target gene analysis reveals novel downstream PTEN and TNC genes required for drug-resistance and metastasis in lung cancer. Nucleic Acids Res 43: 1593-1608, 2015.

37. Meng F, Henson R, Wehbe-Janek H, Ghoshal K, Jacob ST and Patel T: MicroRNA-21 regulates expression of the PTEN tumor suppressor gene in human hepatocellular cancer. Gastroenterology 133: 647-658, 2007. 